\title{
Effects of Elasticity on Wall Shear Stress in Patient-Specific Aneurysm of Cerebral Artery
}

\author{
Ryuhei Yamaguchi1 ${ }^{*}$, Taihei Kotani2, Gaku Tanaka2, Simon Tupin1, Kahar Osman3, \\ Nadia Shaira Shafii ${ }^{3}$, Ahmad Zahran Md Khudzari ${ }^{3}$, Kazuhiro Watanabe ${ }^{4}$, Hitomi Anzai1, \\ Atsushi Saitos, Makoto Ohta $^{1}$
}

${ }^{1}$ Institute of Fluid Science, Tohoku University, Miyagi, Japan

${ }^{2}$ Graduate School of Engineering, Chiba University, Chiba, Japan

${ }^{3}$ School of Biomedical Engineering and Health Sciences, Faculty of Engineering, Universiti Teknologi Malaysia, Johor Bahru, Malaysia

${ }^{4}$ Graduate School of Biomedical Engineering, Tohoku University, Miyagi, Japan

${ }^{5}$ Department of Neurosurgery, Sendai Medical Center, Miyagi, Japan

Email: *yryuhei63@gmail.com

How to cite this paper: Yamaguchi, R., Kotani, T., Tanaka, G., Tupin, S.., Osman, K., Shafii, N.S., Md Khudzari, A.Z., Watanabe, K., Anzai, H., Saito, A. and Ohta, M. (2019) Effects of Elasticity on Wall Shear Stress in Patient-Specific Aneurysm of Cerebral Artery. Journal of Flow Control, Measurement \& Visualization, 7, 73-86. https://doi.org/10.4236/jfcmv.2019.72006

Received: September 21, 2018

Accepted: February 16, 2019

Published: February 19, 2019

Copyright $\odot 2019$ by author(s) and Scientific Research Publishing Inc. This work is licensed under the Creative Commons Attribution International License (CC BY 4.0).

http://creativecommons.org/licenses/by/4.0/

\begin{abstract}
The behavior of wall shear stress (WSS) was previously reported in a deformable aneurysm model using fluid-structure interactions. However, these findings have not been validated. In the present study, we examined the effect of elasticity (i.e., deformation) on wall shear stress inside a cerebral aneurysm at the apex of a bifurcation using particle image velocimetry in vitro. The flow model simulated a human patient-specific aneurysm at the apex of the bifurcation of the middle cerebral artery. Flow characteristics by wall elasticity were examined for both elastic and non-deformable aneurysm models with pulsatile blood flow. The absolute temporally- and spatially-averaged WSS along the bleb wall was smaller in the elastic model than that in the non-deformable model. This small WSS may be related to attenuation of the WSS. Further, the WSS gradient had a finite value near the stagnation point of the aneurysm dome. Finally, the WSS gradient near the stagnation point was slightly smaller in the elastic model than that in the non-deformable model. These data suggest that elasticity of the aneurysm wall can affect the progression and rupture of aneurysms via hemodynamic stress.
\end{abstract}

\section{Keywords}

Cerebral Aneurysm, Elasticity, Particle Image Velocimetry, Wall Shear Stress

\section{Introduction}

Computational fluid dynamics (CFD) is increasingly used to assess the hemo- 
dynamics that occur inside aneurysms [1] [2] [3] [4], including hemodynamic stress for ruptured and unruptured aneurysms with a rigid vessel wall. Hemodynamic factors, including wall shear stress (WSS), oscillatory shear index, impingement region, and inflow jet, are known risk indicators for aneurysm progression and rupture [5] [6] [7] [8] [9]. Xiang et al. also reported that morphology was an important hemodynamic parameter in discriminating rupture status [8]. However, the mechanism of rupture has not clarified yet [1].

The use of CFD has been compared with a range of methods including phase contrast magnetic resonance imaging (MRI) and particle imaging velocimetry (PIV) [10] [11]. For example, Acevedo-Bolton et al. used in vivo and in vitro phase contrast magnetic resonance imaging to validate CFD simulations in a patient-specific aneurysm model [10]. Ford et al. also used PIV to validate the velocity fields calculated with CFD in two patient-specific aneurysms and found that the detailed flow structure in PIV largely agreed with that in CFD [11]. Further, Sforza et al. described the hemodynamic effects of perianeurysmal structures that caused displacement of the aneurysmal wall in the vertebral artery using yearly computed tomography angiography for 4 years [12]. Finally, Hoi et al. validated the correlation of CFD simulation of a cerebral aneurysm with geometric variation in a rigid aneurysm model [13].

A limitation of these studies of ruptured and unruptured aneurysms is the restriction to aneurysms with a rigid wall, while an aneurysm wall is normally thin and deformable. The flow behavior for models with an elastic vascular wall has been investigated in CFD. For example, the fluid-structure interaction during pulsatile blood flow is widely used to investigate the influence of wall elasticity on hemodynamics [3] [14] [15] [16] [17]. These studies reported that arterial wall deformation plays an important role in WSS distribution. However, because of the lack of suitable experimental techniques, including availability of an elastic phantom model, it is difficult to validate these results. Lee et al. described flow behavior in an elastic aneurysm model [17], although the aneurysm wall was too thick, and the wall elasticity was larger than that of human cerebral vessels [18]. Yagi et al. [19] also reported a patient-specific aneurysm model with an elasticity of $0.96 \pm 0.115 \mathrm{MPa}$, although wall thickness of $1.0 \pm 0.3 \mathrm{~mm}$ (i.e., $0.7-1.3 \mathrm{~mm}$ ) for an aneurysm neck size of $4.3 \mathrm{~mm}$ was too thick. Further, a diseased aneurysm wall may be affected by hypertension and have greater elasticity than health vessels. Thus, studies examining the effect of wall elasticity on WSS are required under conditions of suitable wall thickness.

Using PIV and fluid-structure interactions, the temporally- and spatially-averaged WSS in an idealized spherical elastic thin-walled model was reported as 7\% less than that in a rigid model [20] [21]. Nevertheless, the effects of wall elasticity on flow characteristics in a pulsatile blood flow have not been reported in a human patient-specific cerebral aneurysm model. Thus, in the present study, a deformable phantom model of a human patient-specific elastic aneurysm at the apex of the bifurcation in the middle cerebral artery was created. The aim of this study was to determine the effects of wall elasticity on the absolute 
temporally- and spatially-averaged value of WSS and the WSS gradient in a patient-specific model.

\section{Methods}

\subsection{Morphology}

The morphology of a human patient-specific aneurysm at the apex of the bifurcation of the middle cerebral artery (MCA) (M1 bifurcates to M2 and M3) is shown in Figure 1. Two efferent vessels M2 and M3 bifurcate from the afferent vessel M1. The left side shows the contour and the wall thickness in the mid-sagittal plane at section S-S'. The contour and the wall thickness at the mid-sagittal plane at the section S-S' is depicted. The plane perpendicular to the mid-sagittal plane is approximately regarded as a semi-symmetrical plane within the bleb. According to Tobe et al., bleb walls are apt to rupture at a thickness of $50-320 \mu \mathrm{m}$ [22]. A thickness of $0.3 \mathrm{~mm}$ was selected to simulate the wall thickness in the full-scale model. The wall thickness in our 3.25-fold model was approximately $1.0 \mathrm{~mm}(0.30 \times 3.25 \mathrm{~mm})$. The inlet diameter $\mathrm{d}_{0}$ was $2.46 \mathrm{~mm} \times 3.25$ $=8.0 \mathrm{~mm}$. The aneurysm neck size $(\mathrm{N})$ was $9.8 \mathrm{~mm}$; the depth $(\mathrm{D})$ was $12.1 \mathrm{~mm}$; the lateral height $(\mathrm{H})$ was $22.0 \mathrm{~mm}$; the bleb neck $\left(\mathrm{d}_{\mathrm{b}}\right)$ was $6.8 \mathrm{~mm}$, and the aspect ratio was 1.23 [23]. Although the actual vessel consists of three layers, our model was based on one layer.

\subsection{Phantom Model}

The elastic phantom model was fabricated using photo stereolithographic technology as follows. According to stl (stereolithography) data, the (inner) body of the aneurysm model was enclosed by the outer wall with a space (gap) of 1.2 $\mathrm{mm}$. Silicone elastomer was injected into this space. After the silicone elastomer hardened, the inner and the outer bodies enclosing this space were removed. The pathological image is shown in Figure 2. There are two white thicker hypertrophic regions, and two red thin-walled regions that consist of thin internal elastic lamina without endothelial cells, intima, or smooth muscle cells.

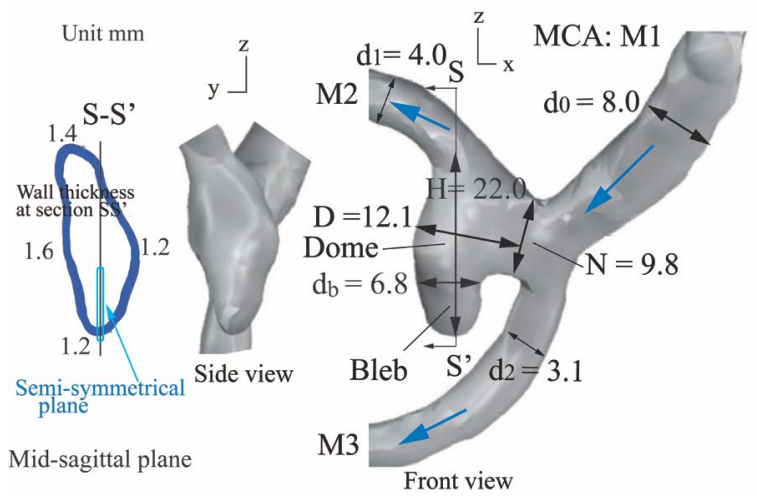

Figure 1. Morphology, measurement section and wall thickness of the patient-specific model. D: depth, $\mathrm{H}$ : lateral height, $\mathrm{N}$ : aneurysm neck width of aneurysm dome, $\mathrm{d}_{\mathrm{b}}$ : neck diameter of bleb. 
The red, belt-like, thin-walled regions correspond to the vicinity of the stagnation point $S$ where the impingement jet of fluid flow collided, and the bleb bottom $\mathrm{B}$. The two thin-walled regions of the aneurysm wall will be prone to injury. Based on the pathological image shown in Figure 2, the silicon elastomer was painted to form hypertrophic regions (1.6 $\mathrm{mm}$ thick), which are thicker than the regions around the stagnation point and the bleb tip. The afferent and efferent walls had a thickness of $2.0 \mathrm{~mm}$ to prevent unstable movement of the aneurysm during pulsatile flow.

The non-deformable model was made of silicone elastomer. First, the aneurysm mold was created from plaster using a 3D printer, and then was embedded in the block filled with silicone elastomer. After the silicone elastomer hardened, the plaster mold was removed by dissolving the plaster in water. The elastic and non-deformable models are shown in Figure 3(a) and Figure 3(b), respectively.

The aneurysm wall was made from silicone with an elasticity of $\mathrm{E}=0.5 \mathrm{MPa}$ (KE-1606; Shin-Etsu Chemical, Tokyo, Japan). The elasticity was measured using a tensile tester machine (EZ-S; Shimadzu, Kyoto, Japan) with the 8th dumbbell-shaped test piece [24].

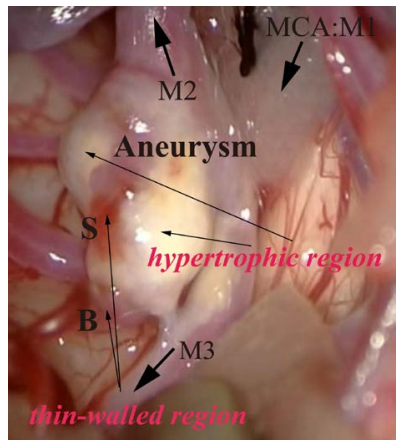

Figure 2. Pathological image of patient-specific cerebral aneurysm.

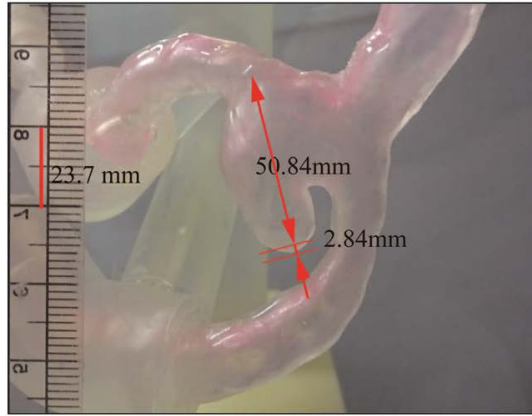

(a)

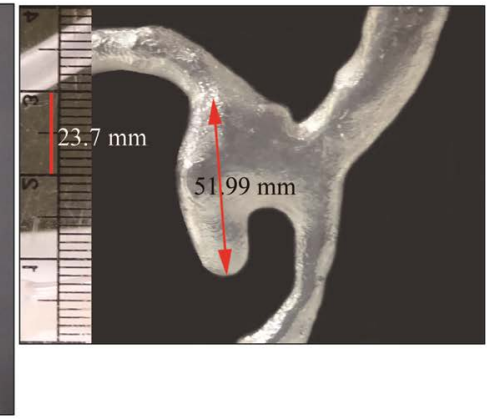

(b)

Figure 3. Phantom of the 3.25-fold patient-specific model. (a) Elastic model; (b) Non-deformable model. The scale of both models was the same (i.e., the left panel $10 \mathrm{~mm}$ scale in both panels corresponds to $23.7 \mathrm{~mm}$ ). In (a), the height $(\mathrm{H})$ is $50.84 \mathrm{~mm}$ after subtracting wall thickness $2.84 \mathrm{~mm}$ (wall thickness $\mathrm{t}=1.2 \mathrm{~mm} \times 2.37$ : magnification). In (b), the height is $51.99 \mathrm{~mm}$. Given the $2.37 \times$ magnification, the elastic and non-deformable model height are $21.5 \mathrm{~mm}$ and $21.9 \mathrm{~mm}$, respectively. The reference height is $22.0 \mathrm{~mm}$ in Figure 1. 


\subsection{Measurement}

The working fluid was $51.5 \%$ aqueous glycerin with a refractive index of 1.41 (identical to that of the silicone elastomer), a density of $\rho=1.14 \mathrm{~g} / \mathrm{cm}^{3}$, and a kinematic viscosity of $v=5.325 \times 10^{-6} \mathrm{~m}^{2} / \mathrm{s}$ at $299 \mathrm{~K}\left(26^{\circ} \mathrm{C}\right)$. After being charged from the roller pump controlled every $0.25 \mathrm{~s}$ (see Figure 4), the working fluid entered into the phantom aneurysm model through a straight afferent tube (length, $320 \mathrm{~mm}$ ). Inside the aneurysm model, the flow bifurcated into two efferent tubes was adjusted with at the same flow rate $\mathrm{Q}_{2} / \mathrm{Q}_{3}=1.0 \pm 0.04\left(\mathrm{Q}_{2}\right.$ and $\mathrm{Q}_{3}$ represent the flow rate through vessels $\mathrm{M} 2$ and $\mathrm{M} 3$, respectively). The standard deviation of the flow ratio was $4 \%$, which was created using a relatively large flow resistance (tube length, $320 \mathrm{~mm}$; inner diameter, $8.0 \mathrm{~mm}$ ). The working fluid flow was calculated using and the standard deviation of flow ratio is $4 \%$.; by creating a relatively large flow resistance through a straight afferent tube (length, $320 \mathrm{~mm}$ and an inner diameter, $8.0 \mathrm{~mm}$ ). The working fluid flow was measured using ultrasonic flow meters (TS410; Transonic System).

In the PIV system, the light source was used to measure the velocity vector was a $15-\mathrm{Hz}$ dual-pulse YAG laser with $30-\mathrm{mJ}$ output and a pulse interval ranging of 350 to $1600 \mu \mathrm{s}$. A cylindrical lens produced a laser sheet thickness of 0.3 $\mathrm{mm}$, in which was irradiated perpendicular to the mid-sagittal plane of the aneurysm model. Scattered radiation from the tracer particles was recorded with an Image Intense CCD camera $(1376 \times 1040$ pixels, Lavision, Göttingen, Germany) fitted with an AF NIKKOR lens (Nikon, Tokyo, Japan) positioned at the mid-sagittal plane of the aneurysm. The measurement was performed with an interrogation window size of $16 \times 16$ pixels with $50 \%$ overlap. The velocity vector can be estimated from one pixel of $0.0124 \mathrm{~mm}$ in the measurement field. We can estimate the velocity vector within a $0.198 \times 0.198 \mathrm{~mm}$ space by considering particle numbers. WSS in the present experiment was estimated from the tangential velocity along the aneurysm wall at approximately $0.20-0.24 \mathrm{~mm}$ from the wall.

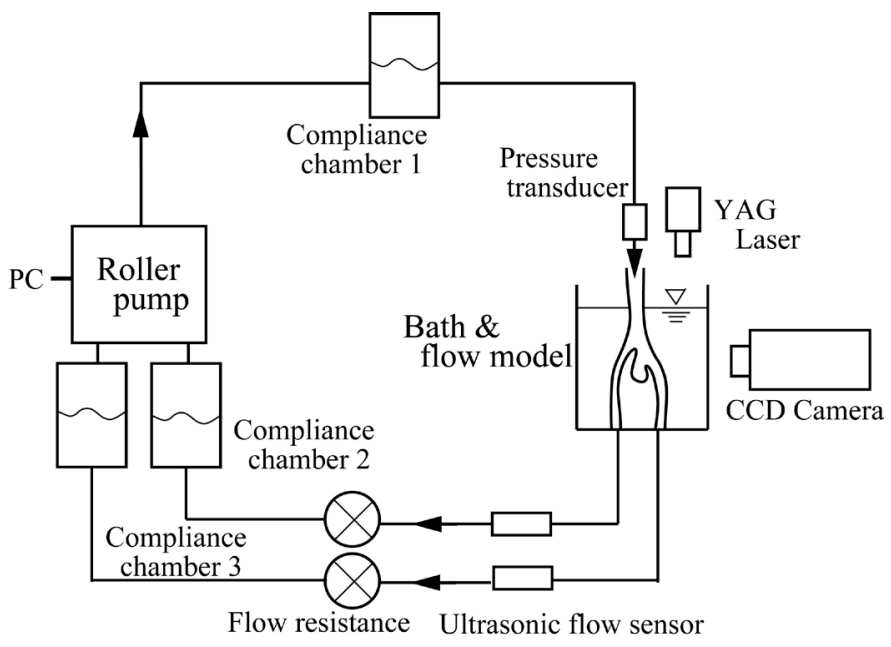

Figure 4. Flow circuit for experiment rig. 
The scatter material was composed of fluorescent particles $14 \mu \mathrm{m}$ in diameter. The velocity vector images were obtained as the averaged image through 50 cardiac cycles. Trigger was set up at same phase for the roller pump (every $0.25 \mathrm{~s}$ ) and was controlled by LabVIEW (National Instruments, USA, Texas). Digital images were processed with DaVis 7 software (LaVision, Göttingen, Germany).

\subsection{Experimental Conditions}

The pulsatile blood flow wave form at inlet M1, which simulates the flow wave form of Valen-Sendstad et al. [25], is shown in Figure 5(a). The maximum and mean Reynolds numbers were $R e_{\max }=680$ and $R e_{\mathrm{m}}=U \mathrm{~d}_{0} / v=435$, respectively, where $\mathrm{d}_{0}$ is the diameter of the afferent vessel M1 and $U$ is the mean velocity through the vessel [26]. The pulsatile period and the Womersley number were $T$ $=8.0 \mathrm{~s}$ and $\alpha=1.54$, respectively. The geometry and the flow similarity (i.e. Reynolds number and Womersley number) were similar to those of full-scale model. Wall deformation (the lateral height and the bleb neck diameter) were also measured with an Image Intense CCD camera under dual-pulse YAG laser at the same flow condition. The height and the bleb neck diameter in the aneurysm were measured every $1 / 8^{\text {th }}$ period of pulsatile flow wave without surrounding the working fluid. After measurement, the inner size is estimated from subtracting the wall thickness. Finally, the deformation ratios of the present cerebral aneurysm were defined as follows:

$$
\Delta \mathrm{d}_{\mathrm{b}} / \mathrm{d}_{\mathrm{b}}=\left\{\left(\mathrm{d}_{\mathrm{bmax}}-\mathrm{d}_{\mathrm{b}}\right) / \mathrm{d}_{\mathrm{b}}\right\} \times 100 \%
$$

And

$$
\Delta \mathrm{H} / \mathrm{H}=\left\{\left(\mathrm{H}_{\max }-\mathrm{H}\right) / \mathrm{H}\right\} \times 100 \%
$$

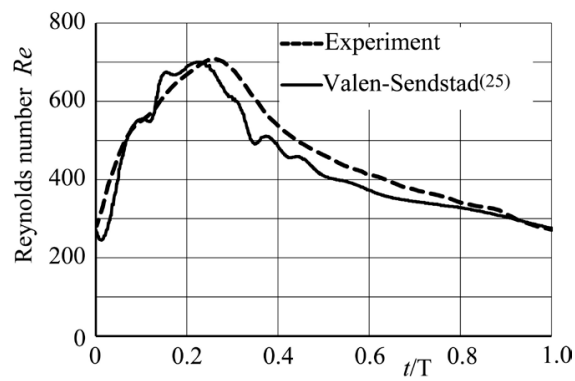

(a)

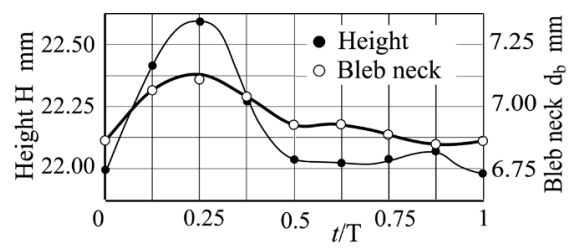

(b)

Figure 5. (a) Boundary condition in afferent vessel $\left(R e_{\mathrm{m}}=435, \alpha=1.54\right)$. The pulsatile flow wave form of Valen-Sendstad is shown for comparison; (b) Deformation of bleb neck diameter $d_{b}$ and lateral height $H$. 
where $d_{b}$ and $d_{b \max }$ represent the minimum and maximum diameters of the bleb neck, respectively, and $\mathrm{H}$ and $\mathrm{H}_{\max }$ represent the minimum and maximum heights, respectively.

\section{Results}

Deformation of the aneurysm height and the bleb neck diameter are shown in Figure 5(b). The height and the bleb neck diameter varied with the pulsatile flow wave form in the M1 vessel. During PIV measurement the wall position could be distinguished from the velocity image data at the same phase during 50 cardiac cycles. The deformation ratios of the bleb neck diameter and the height were $\Delta \mathrm{d}_{\mathrm{b}} / \mathrm{d}_{\mathrm{b}}=4.3 \%$ and $\Delta \mathrm{H} / \mathrm{H}=3.2 \%$, respectively.

Figure 6(a) and Figure 6(b) shows the velocity vector in the semi-symmetric plane inside the elastic and non-deformable aneurysms, respectively, at two typical phases (mid- and peak systoles). The core flow from vessel M1 enters the dome from right to left, and then collides at the stagnation point $\mathrm{S}$. The large vortex in the upper dome rotates clockwise. After the flow collides at the stagnation point, a counter-clockwise vortex appears in the lower dome (i.e. in the bleb). At peak systole $(t / T=0.250$; Figure $6(\mathrm{a})$ ), the flow stream colliding at the stagnation point $S$ shows a unique behavior, with the flow moving upward and then quickly turning downward. Similarly, Figure 6(b) shows the velocity vector in the semi-symmetric plane inside the non-deformable aneurysm model. Although the flow, which moves from right to left over the bleb, is similar to that in the elastic model, the fluid at mid-systole $(t / T=0.125$; Figure $6(\mathrm{~b})$ ) flows with a high velocity from right to left. Inside the bleb there is one counter-clockwise vortex in the upper dome and one clockwise vortex in the lower bleb.

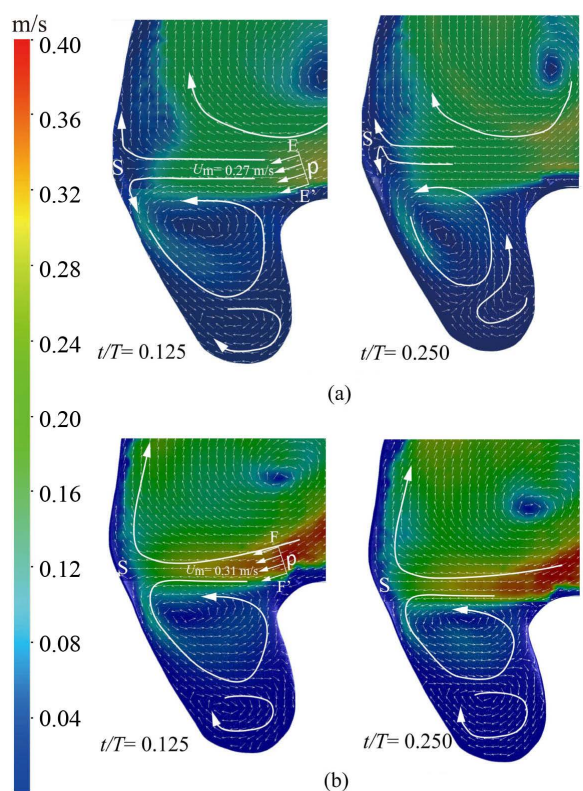

Figure 6. Velocity vector on $\mathrm{x}-\mathrm{y}$ plane at two typical phases in elastic and non-deformable model models: $t / \mathrm{T}=0.125$ (mid-systole), $t / \mathrm{T}=0.250$ (peak systole). (a) Elastic model; (b) Non-deformable model. 
The distribution of WSS along the bleb wall from the dome inlet (o) in the semi-symmetric plane (bar = standard deviation at each point) is shown in Figure 7. The solid S and outline letters S in Figures 7(a)-(d) denote the stagnation point in the non-deformable and elastic and deformable models, respectively. The results were limited along the bottom line of bleb wall in the semi-symmetric plane. This plane is within a few degrees of perpendicular to the aneurysm wall lower bleb and is approximately symmetrical.

WSS distribution indicates the WSS behavior. According to simple CFD, the $\mathrm{z}$-component of WSS is negligible in the region of $\mathrm{s} / \mathrm{d}_{0}<2.8$ with a finite value of the WSS gradient (WSSG). As shown in Figure 5(b), the bleb neck diameter at the mid-systole phase of $t / \mathrm{T}=1 / 8$ ( $1 \mathrm{~s}$ ) (i.e., the average mid-systole phase at $t / \mathrm{T}$ $=1 / 16-3 / 16)$ moves at $0.125 \mathrm{~mm} / \mathrm{s}$ over $1 \mathrm{~s}$ with a bleb neck expansion of 0.125 $\mathrm{mm}$. Thus, the wall displacement over $400 \mu \mathrm{s}$ is $0.125 \mathrm{~mm} / \mathrm{s} \times 400 \times 10^{-6} \mathrm{~s}=$ $0.050 \mathrm{~mm}$. The effect of wall displacement of $0.2-\mathrm{mm}$ will be $0.050 / 0.20=0.25$ (i.e., 25\%. maximum). The magnitude of WSS along the bleb wall in the elastic model was globally smaller than that in the non-deformable model, except at the bleb bottom B. Around the bleb bottom B, WSS was very small or zero in both models. WSS varied throughout the cardiac cycle and the WSSG had a finite value around the point o'. WSSG corresponds to the oscillatory shear index and may be associated with the progression and rupture of aneurysms [9] [26].

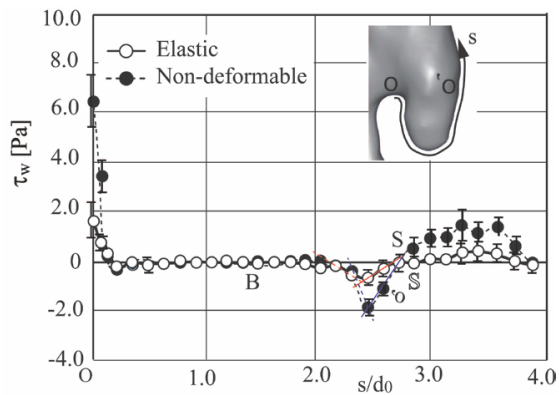

(a)

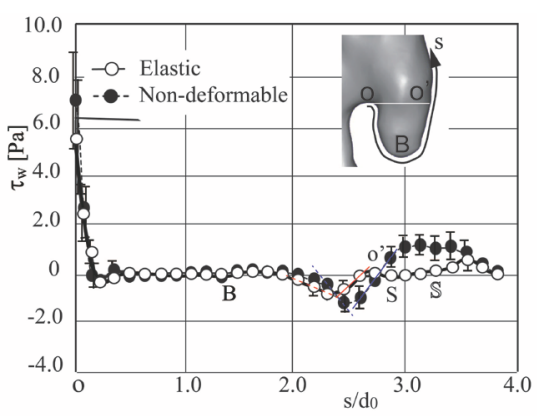

(c)

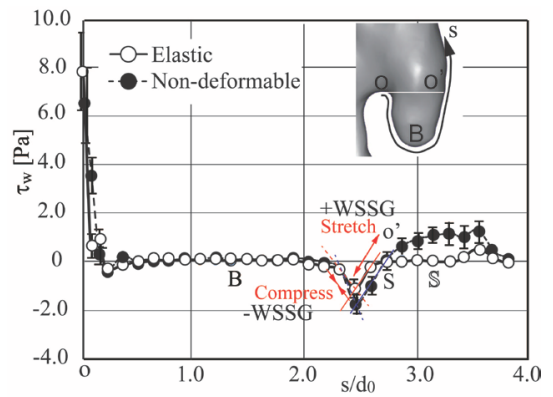

(b)

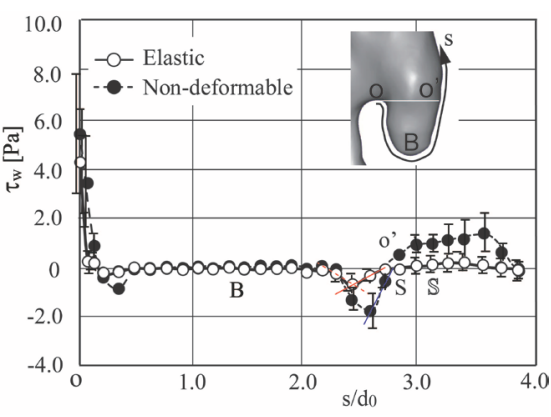

(d)

Figure 7. Comparison of wall shear stress (WSS) in the elastic versus non-deformable models at four typical phases. B and S denote the bleb bottom and stagnation points of elastic and non-deformable models, respectively. (a) $t / \mathrm{T}=0.00$ (early systole); (b) $t / \mathrm{T}=$ 0.125 (mid-systole); (c) $t / \mathrm{T}=0.250$ (peak systole); (d) $t / \mathrm{T}=0.375$ (mid-diastole). 


\section{Discussion}

There are limited data on the effect of wall elasticity on WSS in an experimental patient-specific model. Thus, in the present study we examined the effect of wall elasticity on WSS in a patient-specific aneurysm model under pulsatile blood flow using PIV in vitro. A comparison of the velocity around the bleb (Figure $6(\mathrm{a})$ vs Figure $6(\mathrm{~b}))$ at mid-systole $(t / \mathrm{T}=0.125)$ showed that the mean velocity across section EE' (Figure $6(\mathrm{a}))$ in the elastic model $\left(U_{\mathrm{m}}=0.27 \mathrm{~m} / \mathrm{s}\right)$ was slightly smaller than that across section FF' (Figure 6(b)) in the non-deformable model $\left(U_{\mathrm{m}}=0.31 \mathrm{~m} / \mathrm{s}\right.$ ) through the dome inlet. In these sections EE' and FF', the mean velocity $U_{\mathrm{m}}$ became globally high. The difference in mean velocity between the elastic and non-deformable models may be related to wall deformation. The global flow rate entering into dome is thought to pass through this cross section with these velocities $U_{\mathrm{m}}$ in approximately uniform velocity profile. Because of pulsatile flow, the volume change in the elastic aneurysm was estimated to increase by approximately $\left(1+\Delta \mathrm{d}_{\mathrm{b}} / \mathrm{d}_{\mathrm{b}}\right)^{2} \times(1+\Delta \mathrm{H} / \mathrm{H})-1=0.123$ (i.e. $\left.12.3 \%\right)$. When comparing of velocity $U_{\mathrm{m}}=0.27 \mathrm{~m} / \mathrm{s}$ in the elastic model with that of velocity $U_{\mathrm{m}}=0.31 \mathrm{~m} / \mathrm{s}$ in the non-deformable model, the flow rate which is proportional to mean velocity through its section, this difference of mean velocity change $\Delta U_{\mathrm{m}} / U_{\mathrm{m}}(0.31-0.27 / 0.31)$ in the elastic aneurysm model is approximately $12.9 \%$. This is one of approximate comparison for the deformation. Where the deformation ratios of the bleb neck diameter and the height were $\Delta \mathrm{d}_{\mathrm{b}} / \mathrm{d}_{\mathrm{b}}=4.3 \%$. and $\Delta \mathrm{H} / \mathrm{H}=3.2 \%$, respectively, which correspond to pathological data (3\% - 7\%). [27] [28] [29]. Cebral et al. reported a maximum wall deformation of $0.6 \mathrm{~mm}$ over 12 time-points pathologically [30].

In the present study, WSS was very small near the bleb tip, and with no difference between the elastic and non-deformable models. The absolute temporally- and spatially-averaged value of WSS at the four phases was $0.42 \mathrm{~Pa}$ in the elastic model, which was approximately 50\% smaller than that in the non-deformable model (from $\mathrm{s} / \mathrm{d}_{0}=0-3.8$ ). The degree of WSS reduction was approximately $7 \%$ when comparing of the elastic model with the rigid model in the ideal spherical aneurysm model [21]. The degree of WSS reduction depends on the morphology of patient-specific models. Thus, the WSS may be sensitive to overestimation in the non-deformable model compared with that in the elastic model.

The attenuation of WSS may release the hemodynamic force against the vessel wall as previously reported by Torii et al. [3]. As shown in Figure 2, there are two thin-walled regions that consist of thin internal elastic lamina without endothelial cells, intima, or smooth muscle cells. The red, belt-like, thin-walled regions correspond to the vicinity of the stagnation point $S$ where the impingement jet of fluid flow collided. The two thin-walled regions of the aneurysm wall will be prone to injury. There was a site with a negative WSSG immediately adjacent to a site with a positive WSSG. When the afferent vessel diameter of $d_{0}=$ $2.46 \mathrm{~mm}$ in the full-scale model is defined as the characteristic length, the di- 
mensional WSSG along the distance along the aneurysm wall can be estimated using a full-scale model. The WSS in the afferent vessel was $2.42 \mathrm{~Pa}$ at mean velocity; the same distribution of WSS is expected in a full-scale model. In Figure 7(b) (at mid-systole), WSSGs around point o' in the elastic model ranged from $+2.93 \mathrm{~Pa} / \mathrm{mm}$ to $-3.25 \mathrm{~Pa} / \mathrm{mm}$ (Table 1 ). By contrast, WSSGs in the non-deformable model range from $+3.09 \mathrm{~Pa} / \mathrm{mm}$ to $-5.20 \mathrm{~Pa} / \mathrm{mm}$. Generally, the absolute value in the non-deformable model is slightly larger than that in the elastic model through the cardiac cycle.

As indicated in the elastic model in Figure 7(b), the absolute temporally- and spatially-averaged value of WSS was smaller than that in non-deformable model. Further, the range of WSSG values in elastic model $(+2.93 \mathrm{~Pa} / \mathrm{mm}$ to -3.25 $\mathrm{Pa} / \mathrm{mm})$ was smaller than those of non-deformable model $(+3.09 \mathrm{~Pa} / \mathrm{mm}$ to $-5.20 \mathrm{~Pa} / \mathrm{mm}$ ) around the point o'. These positive and negative WSSGs imply stretching and compression, respectively, of the vascular lumen [9] [26]. The stretching and compression might cause local damage, including aneurysm rupture, in the thin-walled region. Our models used only one experimental hemodynamic approach that excluded cell mechanics (i.e., a biological approach). Thus, the correspondence between stretching and compression is closely associated with the pathological data in Figure 2. The positive WSSG is comparable to a report describing the potential for aneurysm initiation at the apex of the bifurcation [6] [9]. By contrast, a negative WSSG is generally associated with the initiation of atherosclerosis. This hemodynamic stress cyclically affects the same site throughout the cardiac cycle. The WSSG in the non-deformable model may be slightly larger than that in the elastic model through four cyclic phases.

To date, the relationship between the pathology and hemodynamics has been locally examined assuming a non-deformable wall. For example, in a CFD study examining the relationship between pathological data and hemodynamics in human cerebral aneurysms [22], WSS was low and static pressure was slightly high in the thin-walled region. Generally, aneurysm initiation at the apex of a bifurcation occurs with a unique combination of WSSG [26]. In particular, hemodynamic forces such as a smaller finite WSSG in the elastic model may associate with a slower progress and rupture of the aneurysm comprising with non-deformable model [1] [9].

Table 1. Comparison of WSSG around stagnation point in elastic versus non-deformable models.

\begin{tabular}{ccccc}
\hline \multirow{2}{*}{ Time $t / \mathrm{T}$} & \multicolumn{2}{c}{ Positive WSSG $(\mathrm{Pa} / \mathrm{mm})$} & \multicolumn{2}{c}{ Negative WSSG $(\mathrm{Pa} / \mathrm{mm})$} \\
\cline { 2 - 5 } & Elastic wall & Non-deformable wall & Elastic wall & Non-deformable wall \\
\hline 0 & +1.62 & +3.25 & -1.30 & -5.20 \\
0.125 & +2.93 & +3.09 & -3.25 & -5.20 \\
0.250 & +1.62 & +3.25 & -0.65 & -0.65 \\
0.375 & +1.95 & +4.88 & -1.95 & -5.53 \\
\hline
\end{tabular}




\section{Conclusion}

In summary, the elasticity of the aneurysm wall may attenuate the absolute temporally- and spatially-averaged WSS and absolute WSSG. In particularly, the small WSSGs were closely associated with slower progression of cerebral aneurysms. The stretching and compression of the aneurysm wall may also affect the progress of cerebral aneurysms. It is possible that differences in our model size and scale effects may cause the discrepancies with other studies. However, the deformation ratio in this study corresponds with clinical data and our distribution of the WSS results globally simulates those in a full-scale model.

\section{Acknowledgements}

The part of the present work was carried out under the Collaborative Research Project of Institute of Fluid Science, Tohoku University. The project codes are J171060 in 2017 and J18I108 in 2018. This research was partially supported by grants with vote number 4F944, School of Biomedical Engineering and Health Sciences, Universiti Teknologi Malaysia (UTM). We gratefully acknowledge the contribution and support the Ministry of Education Malaysia and Research Management Centre, Universiti Teknologi Malaysia.

We also thank Dr. Teruaki Ikeda of TERAL Inc. and Dr. Takashi Fujiwara of Chiba University, who supported the construction of the aneurysm model from the anatomical data and assisted in processing, and Rebecca Tollefson, DVM, from Edanz Group (www.edanzediting.com/ac) for editing a draft of this manuscript.

No human or animal studies were performed by the authors for this article.

\section{Conflicts of Interest}

No benefits in any form have been or will be received from a commercial party related directly or indirectly to the subject of this manuscript.

\section{References}

[1] Shojima, M., Oshima, M., Takai, K., Torii, R., Nagata, K., Shirouzu, I., Morita, A. and Kirino, T. (2005) Role of the Bloodstream Impacting Force and the Local Pressure Elevation in the Rupture of Cerebral Aneurysm. Stroke, 36, 1933-1938. https://doi.org/10.1161/01.STR.0000177877.88925.06

[2] Ahmed, S., Sutalo, I.D., Kavnoudias, H. and Madan, A. (2007) Fluid Structure Interaction Modeling of a Patient Specific Cerebral Aneurysm: Effect of Hypertension and Modulus of Elasticity. 16th Australasian Fluid Mechanics Conference, Crown Plaza, 2-7 December 2007, 75-81.

[3] Torii, R., Oshima, M., Kobayashi, T., Takagi, K. and Tezduyar, T.E. (2005) Influence of Wall Elasticity in Patient-Specific Hemodynamic Simulations. Computers \& Fluids, 36, 160-168. https://doi.org/10.1016/j.compfluid.2005.07.014

[4] Rayz, V.L., Boussel, L., Acevedo-Bolton, G., Martin, A.J., Young, M.T., Lawton, R., Higashida, R. and Saloner, D. (2008) Numerical Simulations of Flow in Cerebral Aneurysms: Comparison of CFD Results and In Vivo MRI Measurements. Journal of Biomechanical Engineering, 130, Article ID: 051011, 1-9. 
https://doi.org/10.1115/1.2970056

[5] Cebral, J.R., Castro, M.A., Burgess, J.E., Pergolizzi, R.S., Sheridan, M.J. and Putman, C.M. (2005) Characterization of Cerebral Aneurysms for Assessing Risk of Rupture by Using Patient-Specific Computational Hemodynamics Models. American Journal of Neuroradiology, 26, 2550-2559.

[6] Meng, H., Wang, Z, Hoi, Y., Gao, L., Metaxa, L., Swartz, D.D. and Kolega, J. (2007) Complex Hemodynamics at the Apex of Arterial Bifurcation Induces Vascular Remodeling Resembling Cerebral Aneurysm Initiation. Stroke, 38, 1924-1931. https://doi.org/10.1161/STROKEAHA.106.481234

[7] Sujan, D.H.M., Tremmel, M., Mocco, J., Kim, M., Yamamoto, J., Siddiqui, A.H., Hopkins, L.N. and Meng, H. (2008) Morphology Parameters for Cerebral Aneurysm Rupture Risk Assessment. Neurosurgery, 63, 185-197. https://doi.org/10.1227/01.NEU.0000316847.64140.81

[8] Xiang, J., Natarajan, S.K., Tremmel, M., Ma, D., Mocco, J., Hopkins, L.N., Shiddiqui, A.H., Levy, E.I. and Meng, H. (2011) Hemodynamic-Morphologic Discriminants for Intracranial Aneurysm Rupture. Stroke, 42, 144-152.

https://doi.org/10.1161/STROKEAHA.110.592923

[9] Dolan, J.M., Kolega, J. and Meng, H. (2013) High Wall Shear Stress and Spatial Gradients in Vascular Pathology: A Review. Annals of Biomedical Engineering, 41, 1411-1427. https://doi.org/10.1007/s10439-012-0695-0

[10] Acevedo-Bolton, G., Jou, L.D., Dispensa, B.P., Lawton, M.T., Higashida, R.T., Martin, A.J. and Saloner, D. (2006) Estimating the Hemodynamic Impact of Interventional Treatments of Aneurysms: Numerical Simulation with Experimental Validation: Technical Case Report. Neurosurgery, 59, E429-E430.

https://doi.org/10.1227/01.NEU.0000223495.39240.9A

[11] Ford, M.D., Nikolov, H.N., Lownie, S.P., DeMont, E.M., Kalata, W., Loth, F., Holdsworth, D.W. and Steinman, D.A. (2008) PIV-Measured versus CFD-Predicted Flow Dynamics in Anatomically Realistic Cerebral Aneurysm Models. Journal of Biomechanical Engineering, 130, Article ID: 021015-1/9.

[12] Sforza, D., Putman, C., Tateshima, S., Vinũela, F. and Cebral, J. (2012) Effects of Perianeurysmal Environment during the Growth of Cerebral Aneurysm: A Case Study. American Journal of Neuroradiology, 33, 1115-1120. https://doi.org/10.3174/ajnr.A2908

[13] Hoi, Y., Woodward, S.H., Kim, M., Taulbee, D.B. and Meng, H. (2006) Validation of CFD Simulations of Cerebral Aneurysms with Implication of Geometric Variation. Journal of Biomechanical Engineering, 128, 844-851. https://doi.org/10.1115/1.2354209

[14] Tada, S. and Tarbell, J.M. (2005) A Computational Study of Flow in a Compliant Carotid Bifurcation-Stress Phase Angle Correlation with Shear Stress. Annals of Biomedical Engineering, 33, 1202-1212. https://doi.org/10.1007/s10439-005-5630-1

[15] Torii, R., Oshima, M., Kobayashi, T., Takagi, K. and Tezduyar, T.E. (2010) Influence of Wall Thickness on Fluid-Structure Interaction Computations of Cerebral Aneurysms. International Journal for Numerical Methods in Biomedical Engineering, 26, 336-347. https://doi.org/10.1002/cnm.1289

[16] Bazilevs, Y., Hsu, M.C., Zhang, Y., Wang, W., Liang, X., Kvamsdal, T., Brekken, R. and Isaksen, J.G. (2010) A Fully-Coupled Fluid-Structure Interaction Simulation of Cerebral Aneurysms. Computational Mechanics, 46, 3-16. https://doi.org/10.1007/s00466-009-0421-4

[17] Lee, C.J., Zhang, Y., Takao, H., Murayama, Y. and Qian, Y. (2013) A Flu- 
id-Structure Interaction Study Using Patient-Specific Ruptured and Unruptured Aneurysm: The Effect of Aneurysm Morphology, Hypertension and Elasticity. Journal of Biomechanics, 46, 2402-2410. https://doi.org/10.1016/j.jbiomech.2013.07.016

[18] Hayashi, K., Handa, H., Nagasawa, S., Okumura, A. and Moritake, K. (1980) Stiffness and Elastic Behavior of Human Intracranial and Extracranial Arteries. Journal of Biomechanics, 13, 175-184. https://doi.org/10.1016/0021-9290(80)90191-8

[19] Yagi, T., Sato, A., Shinke, M., Takahashi, S., Tobe, Y., Takao, H., Murayama, Y. and Umezu, M. (2013) Experimental Insights into Flow Impingement in Cerebral Aneurysm by Stereoscopic Particle Image Velocimetry: Transition from a Laminar Regime. Journal of the Royal Society Interface, 10, Article ID: 20121031. https://doi.org/10.1098/rsif.2012.1031

[20] Okada, K. and Yamaguchi, R. (2011) Structural of Pulsatile Flow in a Model of Elastic Cerebral Aneurysm. Journal of Biorheology, 25, 1-7. https://doi.org/10.1007/s12573-011-0035-2

[21] Xu, L., Sugawara, M., Tanaka, G., Ohta, M., Liu, H. and Yamaguchi, R. (2016) Effect of Elasticity on Wall Shear Stress inside Cerebral Aneurysm at Anterior Cerebral Artery. Technology and Health Care, 24, 349-357. https://doi.org/10.3233/THC-161135

[22] Tobe, Y., Yagi, T., Iwabuchi, Y., Yamanashi, M., Takamura, K., Sugiura, T., Umezu, M., Hayashi, Y., Yoshida, H., Nakajima, A., Nishimura, K., Okada, Y., Sugawara, M., Hiraguchi, S., Kudo, T. and Kitahara, S. (2014) Relationship between Pathology and Hemodynamics of Human Unruptured Cerebral Aneurysms. In: Goh, J., Ed., The 15th International Conference on Biomedical Engineering. IFMBE Proceedings, Vol. 43, Springer, Cham, 44-47. https://doi.org/10.1007/978-3-319-02913-9_12

[23] Ujiie, H., Tamano, Y., Sasaki, K. and Hori, T. (2001) Is the Aspect Ratio a Reliable Index for Predicting the Rupture of a Saccular Aneurysm? Neurosurgery, 48, 495-503. https://doi.org/10.1097/00006123-200103000-00007

[24] Kosukegawa, H., Shida, S., Hashida, Y. and Ohta, M. (2010) Mechanical Properties of Tube-Shape Polyvinyl Alcohol Hydrogel Blood Vessel Biomodel. ASME 20103 rd Joint US-European Fluids Engineering Summer Meeting, Montreal, 1-5 August 2010, 1877-1883.

[25] Valen-Sendstad, K., Mardal, K.A., Mortensen, M., Reif, B.A.P. and Langtangen, H.P. (2011) Direct Numerical Simulation of Transitional Flow in a Patient-Specific Intracranial Aneurysm. Journal of Biomechanics, 44, 2826-2832.

https://doi.org/10.1016/j.jbiomech.2011.08.015

[26] Yamaguchi, R., Tanaka, G. and Liu, H. (2016) Effect of Elasticity on Flow Characteristics inside Intracranial Aneurysms. International Journal of Neurology and Neurotherapy, 3, 049.

[27] Gao, L., Hoi, Y., Swartz, D.D., Kolega, J., Siddiqui, A. and Meng, H. (2008) Nascent Aneurysm Formation at the Basilar Terminus Induced by Hemodynamics. Stroke, 39, 2085-2090. https://doi.org/10.1161/STROKEAHA.107.509422

[28] Meyer, F.B., Huston III, J. and Riederer, S.S. (1993) Pulsatile Increases in Aneurysm Size Determined by Cine Phase-Contrast MR Angiography. Journal of Neurosurgery, 78, 879-883. https://doi.org/10.3171/jns.1993.78.6.0879

[29] Umeda, Y., Ishida, F., Hamada, K., Fukazawa, K., Miura, Y., Toma, N., Suzuki, H., Matsushima, S., Shimosaka, S. and Taki, W. (2011) Novel Dynamic Four-Dimensional CT Angiography Revealing 2-Type Motions of Cerebral Arteries. Stroke, 42, 815-818. https://doi.org/10.1161/STROKEAHA.110.591008 
[30] Cebral, J.R., Mut, F., Sforza, D., Löhner, R., Scrivano, E., Lylyk, P. and Putman, C.M. (2011) Clinical Application of Image-Based CFD for Cerebral Aneurysms. International Journal for Numerical Methods in Biomedical Engineering, 27, 977-992. https://doi.org/10.1002/cnm.1373

\section{Nomenclature}

D: depth of aneurysm

$\mathrm{d}_{\mathrm{b}}$ : diameter of bleb neck

$\mathrm{d}_{0}$ : inlet diameter

$\mathrm{H}$ : lateral height of aneurysm

$\mathrm{N}$ : neck size of aneurysm

$R e_{\mathrm{m}}$ : mean Reynolds number $=U \mathrm{~d}_{0} / v$

T: Period of pulsatile flow

$U$ : mean inlet velocity

$\alpha$ : Womersley number $=\left(\mathrm{d}_{0} / 2\right) \sqrt{2 \pi / v T}$

$v$. kinematic viscosity of working fluid

$\rho$ : density of working fluid

$\tau_{\mathrm{w}}:$ wall shear stress (WSS) 